\title{
3D Printing of Polysaccharide-Based Self-Healing Hydrogel Reinforced with Alginate for Secondary Cross-Linking
}

\author{
Hyun-Ho Roh ${ }^{1,+}$, Hyun-Seung Kim ${ }^{1,+}{ }^{\text {, Chunggoo Kim }}{ }^{1}$ and Kuen-Yong Lee ${ }^{1,2, *(D)}$ \\ 1 Department of Bioengineering, Hanyang University, Seoul 04763, Korea; yes9268@naver.com (H.-H.R.); \\ hyuns9393@naver.com (H.-S.K.); cung4060@nate.com (C.K.) \\ 2 Institute of Nano Science and Technology, Hanyang University, Seoul 04763, Korea \\ * Correspondence: leeky@hanyang.ac.kr; Tel.: +82-2-2220-0482 \\ + These authors contributed equally.
}

check for

updates

Citation: Roh, H.-H.; Kim, H.-S.; Kim, C.; Lee, K.-Y. 3D Printing of Polysaccharide-Based Self-Healing Hydrogel Reinforced with Alginate for Secondary Cross-Linking.

Biomedicines 2021, 9, 1224.

https://doi.org/10.3390/

biomedicines 9091224

Academic Editors: Elvira De Giglio and Maria A. Bonifacio

Received: 9 August 2021

Accepted: 13 September 2021

Published: 15 September 2021

Publisher's Note: MDPI stays neutral with regard to jurisdictional claims in published maps and institutional affiliations.

Copyright: (c) 2021 by the authors. Licensee MDPI, Basel, Switzerland. This article is an open access article distributed under the terms and conditions of the Creative Commons Attribution (CC BY) license (https:// creativecommons.org/licenses/by/ $4.0 /)$.

\begin{abstract}
Three-dimensional (3D) bioprinting has been attractive for tissue and organ regeneration with the possibility of constructing biologically functional structures useful in many biomedical applications. Autonomous healing of hydrogels composed of oxidized hyaluronate (OHA), glycol chitosan (GC), and adipic acid dihydrazide $(\mathrm{ADH})$ was achieved after damage. Interestingly, the addition of alginate (ALG) to the OHA/GC/ADH self-healing hydrogels was useful for the dual cross-linking system, which enhanced the structural stability of the gels without the loss of their selfhealing capability. Various characteristics of OHA/GC/ADH/ALG hydrogels, including viscoelastic properties, cytotoxicity, and 3D printability, were investigated. Additionally, potential applications of 3D bioprinting of OHA/GC/ADH/ALG hydrogels for cartilage regeneration were investigated in vitro. This hydrogel system may have potential for bioprinting of a custom-made scaffold in various tissue engineering applications.
\end{abstract}

Keywords: 3D printing; self-healing hydrogel; secondary cross-linking; polysaccharide; tissue engineering

\section{Introduction}

Three-dimensional (3D) printing technology has been widely used to fabricate various artificial tissues and organs with tissue engineering approaches [1-3]. It can offer improved versatility by delivering accurate control over the spatial distributions of cells as well as biomaterials [4]. The 3D printing technology enables the production of complex tissues with high-resolution precision [5]. The use of biocompatible materials can also lead to biomimetic microenvironments [6]. Hyaluronate (HA) is a naturally occurring polymer and is the main component of the extracellular matrix (ECM) of native cartilage [7,8]. HA can interact with chondrocyte surfaces and has been widely proposed as a suitable material for cartilage regeneration [9-12]. Alginate (ALG) is a potential biomaterial that can be added to improve the inherently unfavorable mechanical properties of HA-based materials in the presence of calcium ions [13].

Hydrogels have been proposed as potential 3D bioinks because of their cell-friendly characteristics [14,15]. They can provide oxygen, nutrients, and growth factors for cells [16]. They can also act as ECM, which can collect cells and fabricate tissue structures [16-18]. Hydrogels are often used in extrusion-based bioprinting $[19,20]$, a field in which significant progress has been made over the last several years [4]. Mechanical dispenser systems are used in extrusion-based bioprinting for depositing bioinks in the form of filaments [1]. They have been successfully used to engineer various tissue constructs, including cartilage, bone, and skin [2]. However, several problems, including the production of shear stress during the extrusion processes, have been obstacles to the printing of hydrogels [21,22]. Shear stress can break hydrogel structures, causing a printed structure fracture $[23,24]$. It can also damage cells, leading to cell death [25]. Therefore, extrusion-based bioprinting requires bioinks that have shear thinning properties in order to overcome these obstacles [26]. 
Self-healing materials can restore their structures and functions after breakage [27-30]. Self-healing hydrogels can be used for extrusion-based printing because of their ability to autonomously heal and recover their mechanical integrity after extrusion through the nozzle [31,32]. The gel-fluid transition caused by shear stress and rapid self-healing ability of hydrogels is an important factor when applying it to 3D printing [33-36].

In this study, hydrogels with self-healing abilities were proposed to overcome these limitations. The aldehyde group of oxidized hyaluronate (OHA) reacted with the amine group of glycol chitosan (GC) to form a Schiff base, thereby forming a hydrogel. The addition of adipic acid dihydrazide (ADH) induced competition between the imine bond (OHA/GC) and the acylhydrazone bond (OHA/ADH), resulting in chemical self-healing. In addition, secondary cross-linking using ALG and calcium ions was confirmed to enhance the mechanical properties and structural stability of $\mathrm{OHA} / \mathrm{GC} / \mathrm{ADH}$ self-healing hydrogels (Figure 1). It was hypothesized that a dual cross-linking system (e.g., covalent crosslinking and ionic cross-linking) could allow for the fabrication of 3D constructs with well-defined structures, prolonged persistence, and reinforced stiffness, compared with conventional covalent self-healing hydrogel systems (e.g., OHA/GC/ADH hydrogel). Self-healing OHA/GC/ADH/ALG hydrogels were fabricated without using any chemical cross-linkers. The self-healing capabilities of the gels were confirmed before starting the second cross-linking process. Chondrogenic differentiation of cells encapsulated in $\mathrm{OHA} / \mathrm{GC} / \mathrm{ADH} / \mathrm{ALG}$ hydrogels was also investigated in vitro.

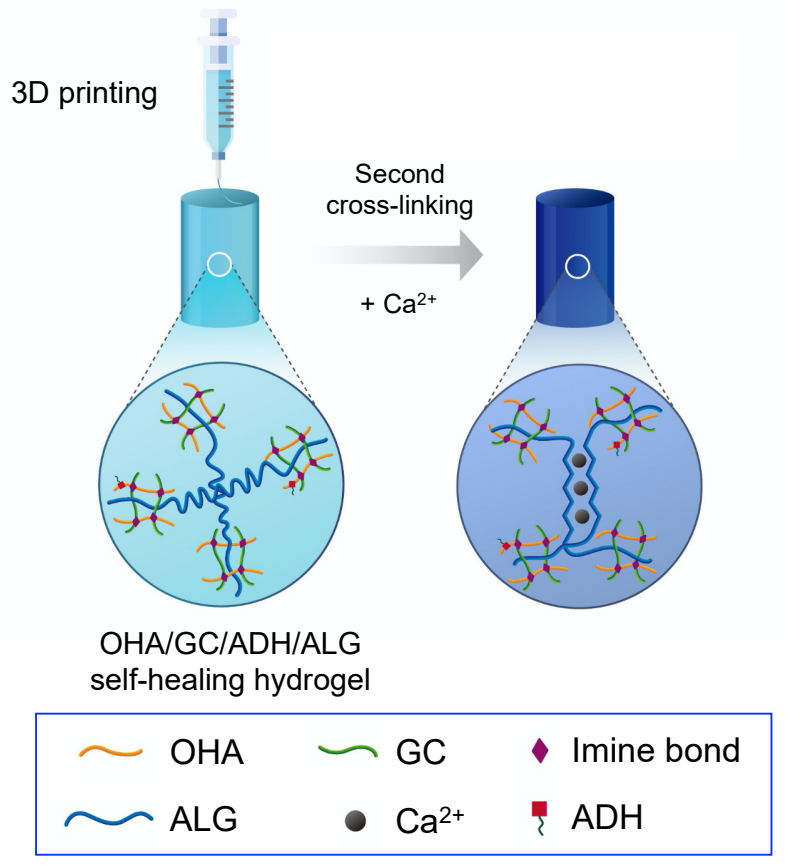

Figure 1. Schematic illustration of fabrication of dual cross-linked 3D construct using an extrusion printing method. Self-healing hydrogel was prepared from oxidized hyaluronate (OHA), glycol chitosan (GC), adipic acid dihydrazide (ADH), and alginate (ALG) by a covalent cross-linking reaction. Second cross-linking was carried out in the presence of calcium ions after the printing process.

\section{Materials and Methods}

\subsection{Materials}

Sodium hyaluronate $(\mathrm{Mw}=2500 \mathrm{kDa}$ ) was purchased from Lifecore (Chaska, $\mathrm{MN}$, USA). Sodium hyaluronate with a molecular weight of $1000 \mathrm{kDa}$ was supplied by Humedix (Anyang, Korea). Sodium alginate $(\mathrm{Mw}=250 \mathrm{kDa}$ ) was purchased from FMC Biopolymer (Sandvika, Norway). GC (Mw $=50 \mathrm{kDa}$ ) was provided by Wako (Osaka, Japan), and 1-Ethyl-3-(dimethylaminopropyl) carbodiimide (EDC) was purchased from Proteochem (Hurricane, UT, USA). N-Hydroxysulfosuccinimide sodium salt (sulfo-NHS) was purchased from Covachem (Loves Park, IL, USA). Adipic acid dihydrazide, sodium periodate, 
2-(N-morpholino)ethanesulfonic acid (MES) hydrate, calcium chloride, human transferrin, and activated charcoal were obtained from Sigma Aldrich (St. Louis, MO, USA). Dulbecco's phosphate-buffered saline (DPBS), fetal bovine serum (FBS), Dulbecco's modified Eagle's medium nutrient mixture F-12 (DMEM/F-12), and penicillin-streptomycin (PS) were supplied by Gibco (Grand Island, NY, USA). A live/dead viability/cytotoxicity kit was purchased from Invitrogen (Waltham, MA, USA).

\subsection{Preparation of Oxidized Hyaluronate and Glycol Chitosan}

HA ( $1 \mathrm{~g})$ was dissolved in $90 \mathrm{~mL}$ of distilled water overnight. Sodium periodate $(0.2673 \mathrm{~g})$ was dissolved in $10 \mathrm{~mL}$ of distilled water, followed by the addition to the HA solution without light. The mixture was left to react for $24 \mathrm{~h}$ to allow for oxidation. The solution was then purified by dialysis against deionized water with sodium chloride for 4 days. The solution was then treated with charcoal and filtered $(0.22-\mu \mathrm{m}$ pore size). The solution $(100 \mathrm{~mL})$ was frozen in a deep freezer at $-80^{\circ} \mathrm{C}$ for $24 \mathrm{~h}$ and then lyophilized for 4 days (FreeZone 6 Liter Benchtop Freeze Dry System, Labconco; Kansas City, MO, USA). GC ( $1 \mathrm{~g})$ was also dissolved in distilled water, and the same process as described above was used to prepare this solution.

\subsection{Hydrogel Fabrication and Characterization}

OHA ( $2 \mathrm{wt} \%)$ and ALG (0.3 wt \%) were dissolved in DPBS overnight and GC (1 wt $\%)$ and $\mathrm{ADH}(0.3 \mathrm{wt} \%)$ were also dissolved in DPBS overnight. Then, the OHA/ALG solution was mixed with the GC/ADH solution to induce the formation of a hydrogel. Fourier transform infrared spectroscopy (Nicolet IS50, Thermo; Waltham, MA, USA) was used to confirm the formation of the aldehyde groups of OHA and the presence of imine and acylhydrazone bonds in the hydrogel. The viscoelastic properties of the hydrogels were measured using a rotational rheometer (Bohlin Gemini 150, Malvern; Worcestershire, UK) equipped with a cone-and-plate fixture $\left(20 \mathrm{~mm}\right.$ diameter plate, $4^{\circ}$ cone angle) at $37^{\circ} \mathrm{C}$.

\subsection{Confirmation of Self-Healing Property of the Hydrogel}

A rotational rheometer (Bohlin Gemini 150, Malvern; Worcestershire, UK) was used to test the self-healing properties of the OHA/GC/ADH/ALG hydrogels $([\mathrm{OHA}]=2 \mathrm{wt} \%$, $[\mathrm{GC}]=1 \mathrm{wt} \%,[\mathrm{ADH}]=0.3 \mathrm{wt} \%,[\mathrm{ALG}]=0.3 \mathrm{wt} \%)$. The oscillatory strain was repeatedly altered from $1 \%$ to $300 \%$ for an evaluation of the self-healing behavior.

\subsection{Three-Dimensional Printing}

A three-dimensional (3D) printer (Invivo, Rokit; Seoul, Korea) was used to fabricate various 3D constructs using an extrusion method. A disposable cartridge was used for printing OHA/GC/ADH/ALG hydrogels. Motor pressure was $300 \mathrm{~N}$ and a 25-guage needle was used as a nozzle. Printing speed and temperature were kept at $8 \mathrm{~mm} / \mathrm{s}$ and $25^{\circ} \mathrm{C}$, respectively. Tinkercad ${ }^{\circledR}$ was used for modeling the 3D constructs (Autodesk; San Rafael, CA, USA). After 3D printing, calcium chloride was added to the printed construct for the formation of ionic cross-linking between ALG and the calcium ions $\left(\left[\mathrm{Ca}^{2+}\right]=60 \mathrm{mM}\right)$. Then, any residual calcium ions were removed by washing the product with DPBS 3 times.

\subsection{Cell Culture}

The ATDC5 cell line was purchased from RIKEN Cell Bank (Tsukuba, Japan) and cells were cultured in a DMEM/F-12 growth medium containing $5 \%$ FBS, $1 \%$ PS, $10 \mu \mathrm{g} / \mathrm{mL}$ human transferrin, and $3 \times 10^{-8} \mathrm{M}$ sodium selenite. Bovine insulin $(10 \mu \mathrm{g} / \mathrm{mL})$ was added to the medium for chondrogenic differentiation. Three-dimensional cultures of ATDC 5 cells were carried out in a spinner flask. OHA/GC/ADH/ALG hydrogels encapsulating ATDC5 cells $\left(1 \times 10^{7}\right.$ cells $\left./ \mathrm{mL}\right)$ were prepared in the shape of disks. Then, the cell-encapsulated gel disks were incubated at $37^{\circ} \mathrm{C}$. 


\subsection{In Vitro Cell Viability}

ATDC 5 cells were seeded in 96-well tissue culture plates ([cell] $=1 \times 10^{5}$ cells per well) for an analysis of the cytotoxicity of the individual hydrogel components. Cells were treated with each component (OHA, GC, ADH, ALG; [polymer] $=500-2000 \mu \mathrm{g} / \mathrm{mL}$ ) solution and $10 \mu \mathrm{L}$ of EZ-cytox was added to each well and incubated for $4 \mathrm{~h}$. The cell viability was then evaluated.

The live/dead assay was performed over $4 \mathrm{~h}$ according to the manufacturer's instructions using ATDC5 cells encapsulated in OHA/GC/ADH/ALG hydrogel disks $\left(1 \times 10^{7}\right.$ cells $\left./ \mathrm{mL}\right)$. Reagent EthD-1 and calcein AM were added to the hydrogel disks. After 30 min of incubation, images were taken using a fluorescence microscope (ECLIPSE TE2000-E, Nikon; Japan). The number of live and dead cells was counted in the images for an evaluation of cell viability.

\subsection{Quantification of Gene Expression}

ATDC 5 cells in gel disks (diameter $=10 \mathrm{~mm}$, thickness $=1 \mathrm{~mm}$ ) were cultured for 3 weeks using media containing bovine insulin $(10 \mu \mathrm{g} / \mathrm{mL})$, and chondrogenic differentiation was evaluated by a reverse transcription polymerase chain reaction (RT-PCR) and real-time PCR analyses.

The cells retrieved from the gel disks were treated with RNAiso Plus reagent (Takara, Japan) for RNA extraction. The expression of chondrogenic marker genes, including SOX9 and collagen type II (COL-2), was evaluated using an RT-PCR thermal cycler machine (Takara). The sequences of the primers were as follows: GAPDH, $5^{\prime}$-CCATCACCATCTTCC AGGAGCGA-3' ' 5'-GGATGACCTTGCCCACAGCCTTG-3' (447 bp); SOX-9, 5' -ATCGGTG AACTGA-GCAGCGAC-3' 5' $^{\prime}$-GCCTGCTGCTTCGACATCCA-3' (200 bp); COL-2, 5' -AAGA GCGGTGACTACTGGATAG-3' , 5'-TGCTGTCTCCATAGCTGAAGT-3' (214 bp). The gene expression level was also quantified by comparison with that of $\beta$-actin, the reference gene cycle threshold, using an ABI PRISM 7500 Real-Time PCR system (Applied Biosystems, Waltham, MA, USA) and SensiMax SYBR (Bioline, Memphis, TN, USA). The sequences of the primers were as follows: $\beta$-actin , $5^{\prime}$-CCCTGAA-CCCTAAGGCCAAC-3'; 5'-GCATACAGGGACAGCACAGC-3'; SOX-9, 5' -AAGTCGGAGAGCCGAGAGCG-3' 5 $^{\prime}$ ACGAAACCGGGGCCACTTGC-3'; COL-2, 5'-CACACTGGTAAGTGGGGCAAGACCG$3^{\prime}$, 5-GGATTGTGTTGTTTCAGGGTTCGGG-3'.

\subsection{Statistical Analysis}

All data are presented as mean \pm standard deviation $(n=4)$.

\section{Results and Discussion}

\subsection{Preparation and Characterization of the OHA/GC/ADH/ALG Hydrogel}

OHA/ALG and GC/ADH solutions were mixed for the preparation of hydrogels. Hydrogel formation was investigated using FT-IR (Figure S1). A peak denoting an aldehyde group $\left(1720 \mathrm{~cm}^{-1}\right)$ appeared after the oxidation reaction of HA, and an imine bond $\left(1456 \mathrm{~cm}^{-1}\right)$ appeared when GC was added. Peaks at $3291 \mathrm{~cm}^{-1}$ and $3323 \mathrm{~cm}^{-1}$, which are derived from the $\mathrm{N}-\mathrm{H}$ symmetric and asymmetric stretching vibrations of acylhydrazone bonds, were also observed.

The effects of alginate on the characteristics of the OHA/GC/ADH gels are listed in Table 1. First, the concentration of alginate was varied between $0.3 \mathrm{wt} \%$ and $1.2 \mathrm{wt} \%$, and the optimum concentration was determined based on the values of the storage shear modulus $\left(G^{\prime}\right)$ and gelation time. The mechanical stiffness decreased as the alginate content increased. Secondary cross-linking improved the mechanical properties of the hydrogel, but an increase in alginate concentration reduced the hydrogel stiffness by more than $0.6 \mathrm{wt} \%$. Therefore, the amount of alginate in OHA/GC/ADH gel was fixed at $0.3 \mathrm{wt} \%$ for further studies.

Next, the gelation kinetics were investigated (Figure 2a). Complete gelation time was determined to be when the storage shear modulus reached a constant value. Gelation gen- 
erally occurs within a few seconds, but complete gelation occurs only after approximately $10 \mathrm{~min}$. OHA/GC/ADH/ALG hydrogels ([OHA] $=2 \mathrm{wt} \%,[\mathrm{GC}]=1 \mathrm{wt} \%,[\mathrm{ADH}]=0.3 \mathrm{wt} \%$, $[\mathrm{ALG}]=0.3 \mathrm{wt} \%$ ) were finally chosen and used for further experiments. The storage shear moduli of the OHA/GC gel, the OHA/GC/ADH gel, and the OHA/GC/ADH/ALG gel were 1630, 670, and $680 \mathrm{~Pa}$, respectively. OHA/GC/ADH and OHA/GC/ADH/ALG hydrogels exhibited similar storage shear moduli (Figure 2b).

A calcium chloride solution was added to generate a second cross-linking between ALG and the calcium ions for enhancing mechanical stiffness and structural stability. The effects of the exposure time and concentration of calcium chloride on the stiffness of the $\mathrm{OHA} / \mathrm{GC} / \mathrm{ADH} / \mathrm{ALG}$ gel were investigated (Figure 2c,d). The storage shear modulus of the OHA/GC/ADH/ALG hydrogel increased with increasing calcium chloride concentration and cross-linking time. The optimum calcium chloride concentration and cross-linking time were determined by measuring the mechanical stiffness and viscosity of the second cross-linked hydrogel.

Table 1. Effect of Second Cross-Linking on Storage Shear Modulus and Gelation Time of OHA/GC/ADH/ALG Self-Healing Hydrogel.

\begin{tabular}{ccccc}
\hline [ALG] $(\mathrm{wt} \%)$ & 0.3 & 0.6 & 0.9 & 1.2 \\
$\mathrm{G}^{\prime}(\mathrm{Pa})$ & $671 \pm 27$ & $535 \pm 57$ & $318 \pm 51$ & $\mathrm{~N} / \mathrm{A}$ \\
complete gelation time & $10 \mathrm{~min}$ & $>20 \mathrm{~min}$ & $>1 \mathrm{~h}$ & $>1 \mathrm{~h}$ \\
$\mathrm{G}^{\prime}$ after second cross-linking $(\mathrm{Pa})$ & $948 \pm 57$ & $712 \pm 71$ & $671 \pm 48$ & $531 \pm 51$ \\
\hline
\end{tabular}

(a)

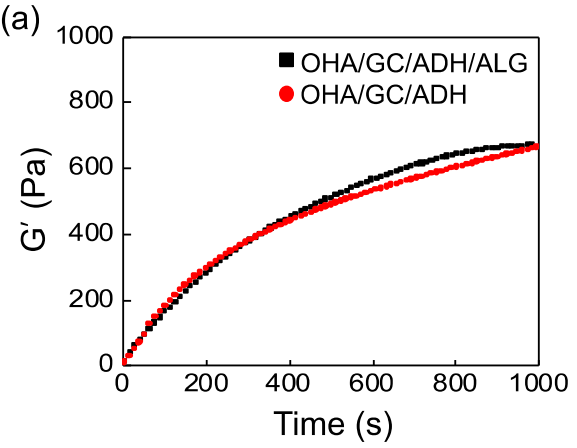

(c)

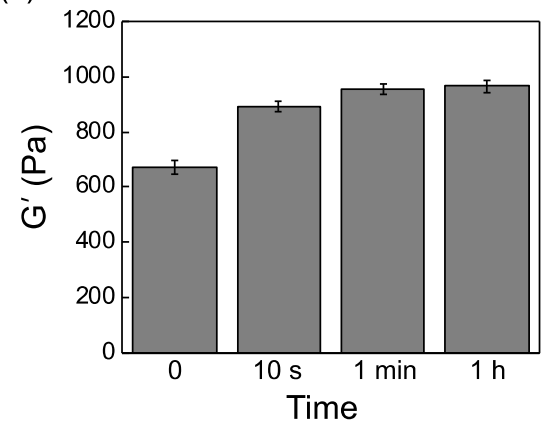

(b)
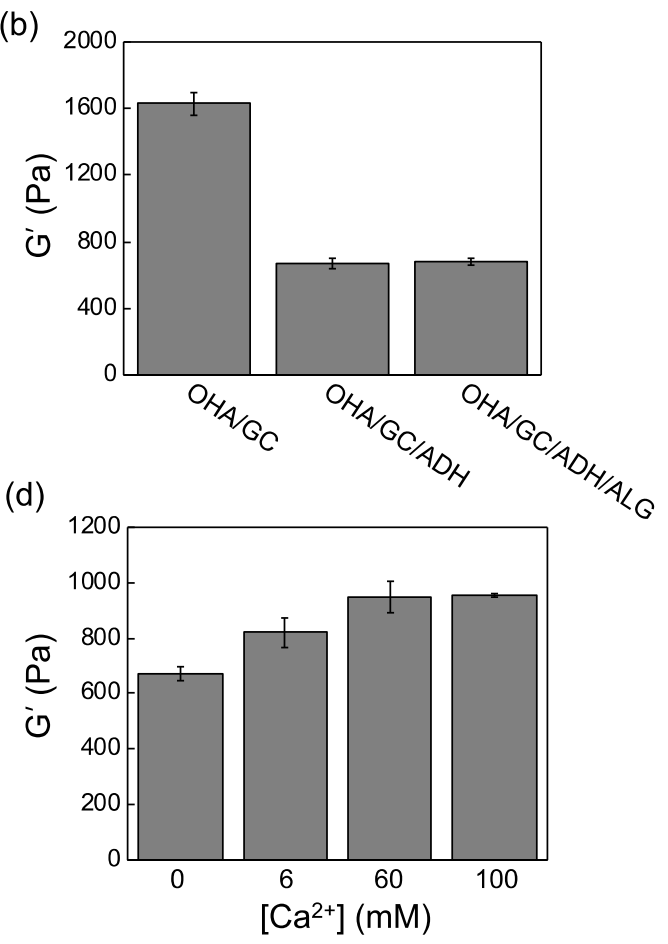

Figure 2. (a) Gelation kinetics of $\mathrm{OHA} / \mathrm{GC} / \mathrm{ADH}$ hydrogels prepared in the presence of ALG (black squares) and in the absence of ALG (red circles). (b) Storage shear moduli of OHA/GC, $\mathrm{OHA} / \mathrm{GC} / \mathrm{ADH}$, and $\mathrm{OHA} / \mathrm{GC} / \mathrm{ADH} / \mathrm{ALG}$ hydrogels $([\mathrm{OHA}]=2 \mathrm{wt} \%,[\mathrm{GC}]=1 \mathrm{wt} \%,[\mathrm{ADH}]=$ $0.3 \mathrm{wt} \%$, [ALG] $=0.3 \mathrm{wt} \%$ ). Storage shear moduli of OHA/GC/ADH/ALG hydrogels prepared with various $(\mathrm{c})$ second cross-linking times $\left(\left[\mathrm{Ca}^{2+}\right]=60 \mathrm{mM}\right)$ and $(\mathrm{d})$ calcium chloride concentrations (cross-linking time $=1 \mathrm{~min}$ ).

The effects of the use of alginate as a secondary cross-linking molecule on the storage modulus and structural stability were next analyzed. A substantial decrease in $\mathrm{G}^{\prime}$ of the OHA/GC/ADH gel was observed after 3 weeks of incubation in DPBS at $37^{\circ} \mathrm{C}$. 
However, the secondary cross-linked OHA/GC/ADH/ALG gel maintained more than $40 \%$ of its $\mathrm{G}^{\prime}$ value after 3 weeks of incubation (Figure 3 ). These results clearly indicate that secondary cross-linking of OHA/GC/ADH/ALG gels can improve the stability of the $\mathrm{OHA} / \mathrm{GC} / \mathrm{ADH}$ gel over a prolonged time period.

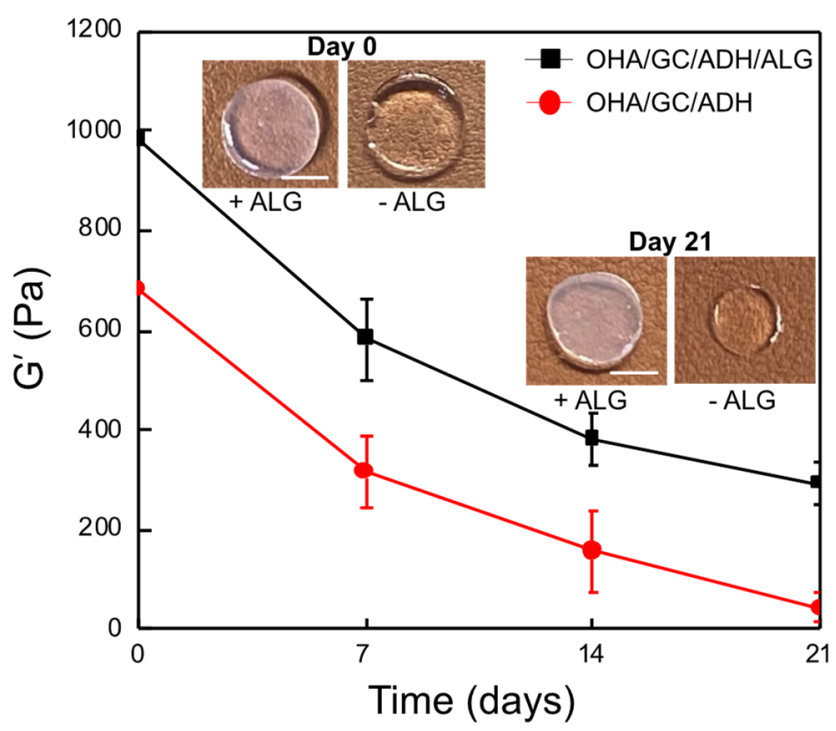

Figure 3. Changes in storage shear moduli of OHA/GC/ADH/ALG hydrogels (black squares) and $\mathrm{OHA} / \mathrm{GC} / \mathrm{ADH}$ hydrogels (red circles) $([\mathrm{OHA}]=2 \mathrm{wt} \%,[\mathrm{GC}]=1 \mathrm{wt} \%,[\mathrm{ADH}]=0.3 \mathrm{wt} \%$, $\left.[A L G]=0.3 \mathrm{wt}^{\mathrm{O}},\left[\mathrm{Ca}^{2+}\right]=60 \mathrm{mM}\right)$. All gel disks (10 $\mathrm{mm}$ diameter, $1 \mathrm{~mm}$ thick $)$ were prepared, treated with calcium ions for second cross-linking $\left(\left[\mathrm{Ca}^{2+}\right]=60 \mathrm{mM}, 1 \mathrm{~min}\right)$, and incubated in DPBS at $37^{\circ} \mathrm{C}$ for 3 weeks (scale bar, $0.5 \mathrm{~mm}$ ).

\subsection{Self-Healing Properties of $O H A / G C / A D H / A L G$ Hydrogels}

A rotational viscometer was utilized to confirm the self-healing behavior of the OHA/GC/ADH/ALG hydrogels. The hydrogel was fabricated and cross-linked through alginate-calcium cross-linking. Next, the storage shear modulus of the hydrogel was measured, and a high strain was applied in order to break the gel structure. When an excess strain $(300 \%)$ was imposed, the loss shear modulus $\left(G^{\prime \prime}\right)$ was higher than the storage shear modulus $\left(\mathrm{G}^{\prime}\right)$, indicating that the hydrogel structure was completely crushed and the gel flow was observed (Figure 4a). Then, the original 1\% strain was applied to the crushed hydrogel. The storage shear modulus of the OHA/GC/ADH/ALG hydrogel immediately recovered to its original value (Figure 4a). The self-healing behavior of the hydrogel could be repeated several times. Macroscopic observation using a cylindrical mold also confirmed the self-healing behavior of the gel (Figure $4 b$ ).

\subsection{Three-Dimensional Bioprinting with Self-Healing Hydrogels}

OHA/GC/ADH/ALG hydrogels were loaded and printed using disposable cartridges (Figure 5a). A strong shear force was applied to the hydrogel during the printing process, which broke the hydrogel structure. However, self-healing occurred immediately, and the hydrogel maintained its fiber form (Figure 5b). The printed fibers were stacked to form a layer-by-layer laminated structure without collapsing. The printed fibers were finally joined together by self-healing to form a single structure. Then, a calcium chloride solution was added to the printed hydrogels to enhance the mechanical stiffness and structural maintenance. The 3D constructs containing ATDC5 cells of various shapes were printed (Figure 5c). 
(a)

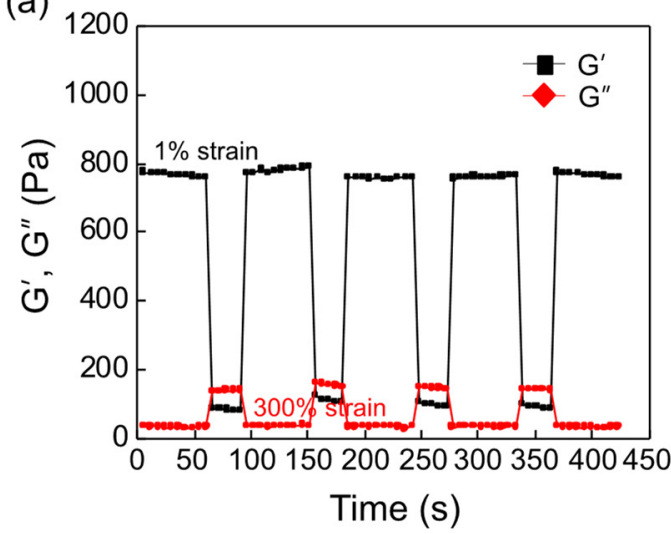

(b)

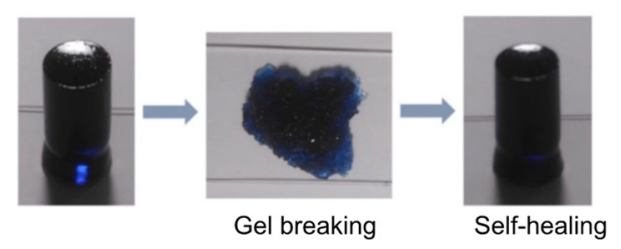

Figure 4. (a) The repeated self-healing behavior of OHA/GC/ADH/ALG hydrogels was confirmed by measuring the viscoelastic properties at $300 \%$ strain $([\mathrm{OHA}]=2 \mathrm{wt} \%,[\mathrm{GC}]=1 \mathrm{wt} \%,[\mathrm{ADH}]=$ $0.3 \mathrm{wt} \%$, [ALG] $=0.3 \mathrm{wt} \%$ ). (b) Macroscopic observation of self-healing behavior of the gel using a cylindrical-shaped mold ( $5 \mathrm{~mm}$ diameter, $10 \mathrm{~mm}$ height). The gel was broken and placed into the mold, and mostly recovered its original shape within $10 \mathrm{~min}$.

(a)

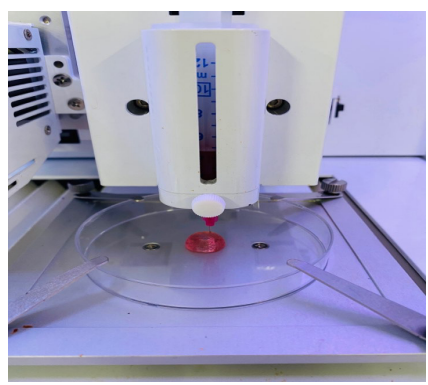

(b)

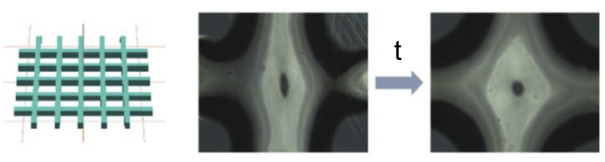

(c)

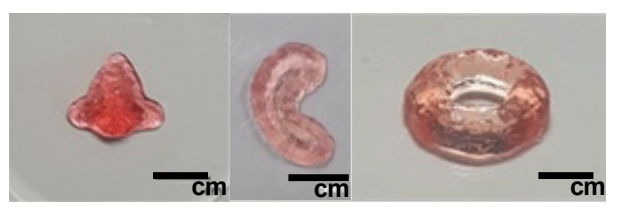

Figure 5. (a) Three-dimensional printing of self-healing OHA/GC/ADH/ALG hydrogel encapsulating ATDC5 cells. (b) Microscopic images of 3D-printed filaments of OHA/GC/ADH/ALG self-healing hydrogel and (c) 3D-printed constructs of various shapes.

\subsection{In Vitro Cell Viability Test}

The cytotoxicity of each component of the hydrogel was evaluated using ATDC 5 cells. OHA, GC, ADH, and ALG showed more than $95 \%$ cell viability even for a high level of material content, indicating that each hydrogel component has low cytotoxicity (Figure S2). A live/dead assay was conducted to determine whether cell viability was influenced by the methods of hydrogel fabrication, cross-linking, and printing. The shear force present during the printing process did not significantly influence cell viability. Furthermore, the second cross-linking process had little effect on cell viability (Figure 6). Therefore, this self-healable bioink system may be utilized for the fabrication of 3D scaffolds for the delivery of cells, drugs, and soluble factors in tissue engineering approaches.

\subsection{Chondrogenic Differentiation In Vitro}

OHA/GC/ADH/ALG hydrogel disks were formed by encapsulating the ATDC5 cells $\left(1 \times 10^{7}\right.$ cells $\left./ \mathrm{mL}\right)$. The disks were cultured in a bioreactor to provide an environment similar to that of the original tissue for 3 weeks. ATDC5 cells in the OHA/GC/ADH/ALG hydrogel maintained high expression level of early gene (SOX-9) at day 7 and high expression level of late gene (COL-2) at day 21 compared with the OHA/GC/ADH hydrogel (Figure 7). This result indicates that secondary cross-linking of OHA/GC/ADH/ALG hydrogels does not substantially influence the chondrogenic gene expression of ATDC5 cells in vitro. 
(a)

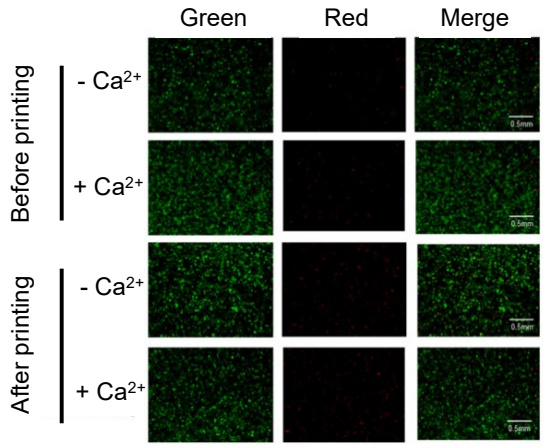

(b)

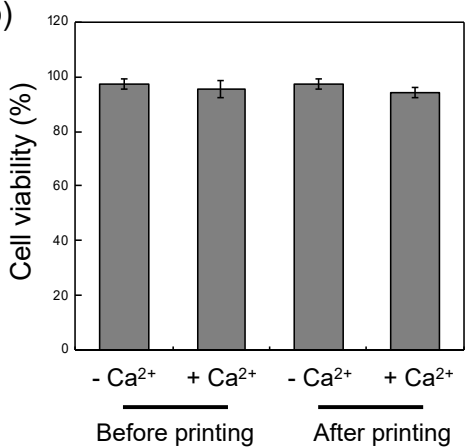

Figure 6. (a) Images of live and dead cells encapsulated within OHA/GC/ADH/ALG hydrogels before and after printing process. Secondary cross-linking of the gels was carried out with calcium ions $\left(+\mathrm{Ca}^{2+}\right)$, and non-cross-linked gels were also used $\left(-\mathrm{Ca}^{2+}\right) .(\mathbf{b})$ Quantitative results from live/dead assays.
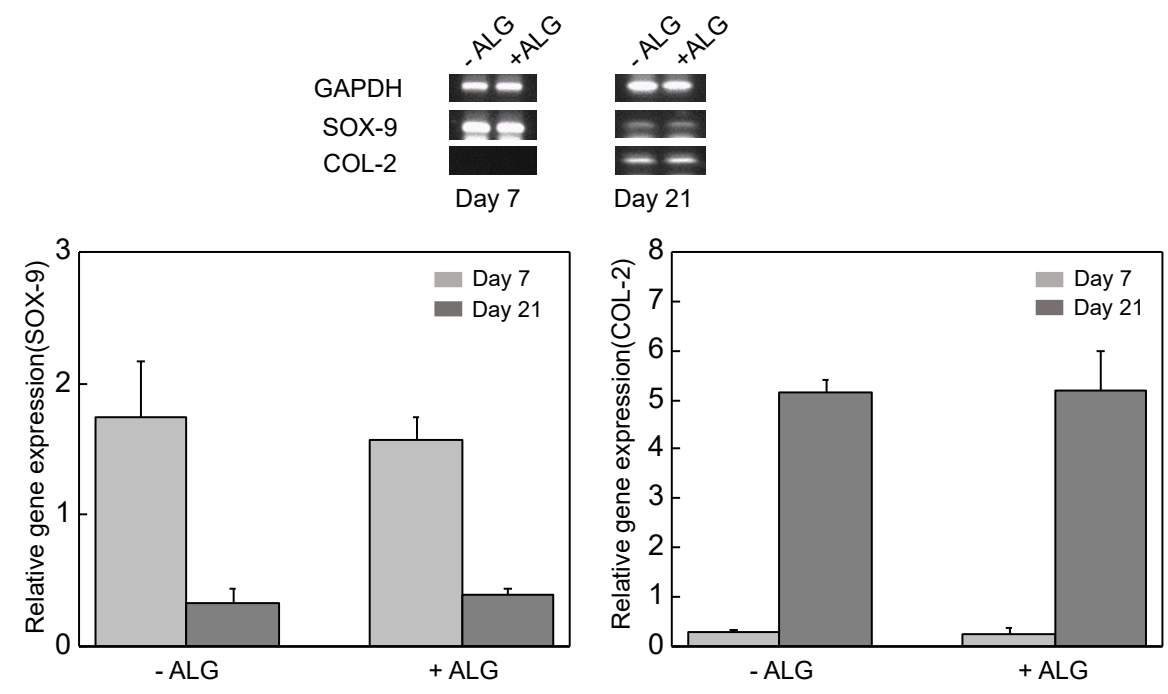

Figure 7. Quantification of gene expression level of ATDC5 cells cultured in vitro. The cells were encapsulated in OHA/GC/ADH gels (-ALG) or OHA/GC/ADH/ALG gels (+ALG) ([OHA] = $\left.2 \mathrm{wt} \%,[\mathrm{GC}]=1 \mathrm{wt} \%,[\mathrm{ADH}]=0.3 \mathrm{wt} \%,[\mathrm{ALG}]=0.3 \mathrm{wt} \%,\left[\mathrm{Ca}^{2+}\right]=60 \mathrm{mM}\right)$.

The gel stiffness is known to be critical in the control of cell phenotype as well as cellular aggregation and chondrogenesis [37-39]. The mechanical stiffness of OHA/GC/ADH/ ALG hydrogel increased after secondary cross-linking (Table 1, Figure 2). However, the change in the gel stiffness was not significant because a small amount of calcium ions was used. Interestingly, secondary cross-linking was useful to enhance the stability of the gels for 3 weeks (Figure 3), which may provide an environment suitable for the chondrogenic differentiation of ATDC5 cells.

\section{Conclusions}

A self-healing hydrogel, based on HA as a base biomaterial, was successfully fabricated with the simple mixture of GC and $\mathrm{ADH}$. This hydrogel system was utilized as a bioink for 3D printing, owing to its self-healing abilities. In addition, secondary cross-linking after the printing process using ALG and calcium ions notably enhanced the mechanical stiffness and structural integrity of the gel. The amount of ALG and degree of ionic cross-linking were optimized for 3D printing based on rheological measurements of the gel, including storage shear modulus and gelation time. Additionally, it was determined that each hydrogel component, the secondary cross-linking process, and the printing process had little effect on the viability of ATDC5 cells encapsulated in the gel. It was also demonstrated that $\mathrm{OHA} / \mathrm{GC} / \mathrm{ADH} / \mathrm{ALG}$ hydrogels can provide a microenvironment 
suitable for chondrogenic differentiation of ATDC5 cells in vitro. This self-healing bioink system may have great potential in many biomedical applications, including tissue and organ regeneration, using a $3 \mathrm{D}$ printer.

Supplementary Materials: The followings are available online at https:/ / www.mdpi.com/article/ 10.3390/biomedicines9091224/s1, Figure S1: FT-IR spectra, Figure S2: Relative cell viability.

Author Contributions: Conceptualization, H.-H.R. and K.-Y.L.; methodology, H.-H.R., H.-S.K. and C.K.; writing-original draft preparation, H.-H.R., H.-S.K. and K.-Y.L.; writing-review and editing, H.-S.K. and K.-Y.L. All authors have read and agreed to the published version of the manuscript.

Funding: This work was supported by a National Research Foundation of Korea (NRF) grant funded by the Korean government (MSIT) (NRF-2020R1A2C1012199).

Institutional Review Board Statement: Not applicable.

Informed Consent Statement: Not applicable.

Data Availability Statement: Not applicable.

Conflicts of Interest: The authors declare no conflict of interest.

\section{References}

1. Dey, M.; Ozbolat, I.T. 3D bioprinting of cells, tissues and organs. Sci. Rep. 2020, 10, 14023. [CrossRef]

2. Murphy, S.V.; Atala, A. 3D bioprinting of tissues and organs. Nat. Biotechnol. 2014, 32, 773-785. [CrossRef] [PubMed]

3. Faramarzi, N.; Yazdi, I.K.; Nabavinia, M.; Gemma, A.; Fanelli, A.; Caizzone, A.; Ptaszek, L.M.; Sinha, I.; Khademhosseini, A.; Ruskin, J.N. Patient-specific bioinks for 3D bioprinting of tissue engineering scaffolds. Adv. Healthc. Mater. 2018, 7, 1701347. [CrossRef] [PubMed]

4. Ozbolat, I.T.; Hospodiuk, M. Current advances and future perspectives in extrusion-based bioprinting. Biomaterials 2016, 76, 321-343. [CrossRef]

5. Pati, F.; Gantelius, J.; Svahn, H.A. 3D bioprinting of tissue/organ models. Angew. Chem. Int. Ed. 2016, 55, 4650-4665. [CrossRef]

6. Nakamura, M.; Kobayashi, A.; Takagi, F.; Watanabe, A.; Hiruma, Y.; Ohuchi, K.; Iwasaki, Y.; Horie, M.; Morita, I.; Takatani, S. Biocompatible inkjet printing technique for designed seeding of individual living cells. Tissue Eng. 2005, 11, 1658-1666. [CrossRef]

7. Allison, D.D.; Grande-Allen, K.J. Hyaluronan: A powerful tissue engineering tool. Tissue Eng. 2006, 12, 2131-2140. [CrossRef]

8. Yoo, H.S.; Lee, E.A.; Yoon, J.J.; Park, T.G. Hyaluronic acid modified biodegradable scaffolds for cartilage tissue engineering. Biomaterials 2005, 26, 1925-1933. [CrossRef] [PubMed]

9. Isacke, C.M.; Yarwood, H. The hyaluronan receptor, CD44. Int. J. Biochem. Cell Biol. 2002, 34, 718-721. [CrossRef]

10. Knudson, C.B.; Knudson, W. Hyaluronan and CD44: Modulators of chondrocyte metabolism. Clin. Orthop. Relat. Res. 2004, 427, S152-S162. [CrossRef]

11. Kurtis, M.S.; Tu, B.P.; Gaya, O.A.; Mollenhauer, J.; Knudson, W.; Loeser, R.F.; Knudson, C.B.; Sah, R.L. Mechanisms of chondrocyte adhesion to cartilage: Role of $\beta 1$-integrins, CD44, and annexin V. J. Orthop. Res. 2001, 19, 1122-1130. [CrossRef]

12. Park, H.; Lee, K.Y. Facile control of RGD-alginate/hyaluronate hydrogel formation for cartilage regeneration. Carbohydr. Polym. 2011, 86, 1107-1112. [CrossRef]

13. Jeon, O.; Song, S.J.; Lee, K.-J.; Park, M.H.; Lee, S.-H.; Hahn, S.K.; Kim, S.; Kim, B.-S. Mechanical properties and degradation behaviors of hyaluronic acid hydrogels cross-linked at various cross-linking densities. Carbohydr. Polym. 2007, 70, $251-257$. [CrossRef]

14. Rutz, A.L.; Hyland, K.E.; Jakus, A.E.; Burghardt, W.R.; Shah, R.N. A multimaterial bioink method for 3D printing tunable, cell-compatible hydrogels. Adv. Mater. 2015, 27, 1607-1614. [CrossRef]

15. Negro, A.; Cherbuin, T.; Lutolf, M.P. 3D inkjet printing of complex, cell-laden hydrogel structures. Sci. Rep. 2018, 8, 17099. [CrossRef]

16. Lee, K.Y.; Mooney, D.J. Hydrogels for tissue engineering. Chem. Rev. 2001, 101, 1869-1880. [CrossRef]

17. Rowley, J.A.; Madlambayan, G.; Mooney, D.J. Alginate hydrogels as synthetic extracellular matrix materials. Biomaterials 1999, 20, 45-53. [CrossRef]

18. Spang, M.T.; Christman, K.L. Extracellular matrix hydrogel therapies: In vivo applications and development. Acta Biomater. 2018, 68, 1-14. [CrossRef]

19. Highley, C.B.; Rodell, C.B.; Burdick, J.A. Direct 3D printing of shear-thinning hydrogels into self-healing hydrogels. Adv. Mater. 2015, 27, 5075-5079. [CrossRef]

20. Chen, Z.; Zhao, D.; Liu, B.; Nian, G.; Li, X.; Yin, J.; Qu, S.; Yang, W. 3D Printing of Multifunctional Hydrogels. Adv. Funct. Mater. 2019, 29, 1900971. [CrossRef]

21. Blaeser, A.; Duarte Campos, D.F.; Puster, U.; Richtering, W.; Stevens, M.M.; Fischer, H. Controlling shear stress in 3D bioprinting is a key factor to balance printing resolution and stem cell integrity. Adv. Healthc. Mater. 2016, 5, 326-333. [CrossRef] 
22. Kim, S.W.; Kim, D.Y.; Roh, H.H.; Kim, H.S.; Lee, J.W.; Lee, K.Y. Three-dimensional bioprinting of cell-laden constructs using polysaccharide-based self-healing hydrogels. Biomacromolecules 2019, 20, 1860-1866. [CrossRef]

23. Narayanan, L.K.; Huebner, P.; Fisher, M.B.; Spang, J.T.; Starly, B.; Shirwaiker, R.A. 3D-bioprinting of polylactic acid (PLA) nanofiber-alginate hydrogel bioink containing human adipose-derived stem cells. ACS Biomater. Sci. Eng. 2016, 2, $1732-1742$. [CrossRef]

24. Nadgorny, M.; Xiao, Z.; Connal, L.A. 2D and 3D-printing of self-healing gels: Design and extrusion of self-rolling objects. Mol. Syst. Des. Eng. 2017, 2, 283-292. [CrossRef]

25. Placone, J.K.; Engler, A.J. Recent Advances in Extrusion-Based 3D Printing for Biomedical Applications. Adv. Healthc. Mater. 2018, 7, 1701161. [CrossRef]

26. Ouyang, L.; Highley, C.B.; Rodell, C.B.; Sun, W.; Burdick, J.A. 3D printing of shear-thinning hyaluronic acid hydrogels with secondary cross-linking. ACS Biomater. Sci. Eng. 2016, 2, 1743-1751. [CrossRef]

27. Jiang, Z.; Diggle, B.; Tan, M.L.; Viktorova, J.; Bennett, C.W.; Connal, L.A. Extrusion 3D printing of polymeric materials with advanced properties. Adv. Sci. 2020, 7, 2001379. [CrossRef] [PubMed]

28. Tu, Y.; Chen, N.; Li, C.; Liu, H.; Zhu, R.; Chen, S.; Xiao, Q.; Liu, J.; Ramakrishna, S.; He, L. Advances in injectable self-healing biomedical hydrogels. Acta Biomater. 2019, 90, 1-20. [CrossRef] [PubMed]

29. Deng, Z.; Wang, H.; Ma, P.X.; Guo, B. Self-healing conductive hydrogels: Preparation, properties and applications. Nanoscale 2020, 12, 1224-1246. [CrossRef]

30. Kuang, X.; Chen, K.; Dunn, C.K.; Wu, J.; Li, V.C.; Qi, H.J. 3D printing of highly stretchable, shape-memory, and self-healing elastomer toward novel 4D printing. ACS Appl. Mater. Interfaces 2018, 10, 7381-7388. [CrossRef]

31. Ko, E.S.; Kim, C.; Choi, Y.; Lee, K.Y. 3D printing of self-healing ferrogel prepared from glycol chitosan, oxidized hyaluronate, and iron oxide nanoparticles. Carbohydr. Polym. 2020, 245, 116496. [CrossRef] [PubMed]

32. Cai, L.; Liu, S.; Guo, J.; Jia, Y.-G. Polypeptide-based self-healing hydrogels: Design and biomedical applications. Acta Biomater. 2020, 113, 84-100. [CrossRef]

33. Zhang, H.; Cong, Y.; Osi, A.R.; Zhou, Y.; Huang, F.; Zaccaria, R.P.; Chen, J.; Wang, R.; Fu, J. Direct 3D printed biomimetic scaffolds based on hydrogel microparticles for cell spheroid growth. Adv. Funct. Mater. 2020, 30, 1910573. [CrossRef]

34. Unagolla, J.M.; Jayasuriya, A.C. Hydrogel-based 3D bioprinting: A comprehensive review on cell-laden hydrogels, bioink formulations, and future perspectives. Appl. Mater. Today 2020, 18, 100479. [CrossRef]

35. Wang, L.L.; Highley, C.B.; Yeh, Y.C.; Galarraga, J.H.; Uman, S.; Burdick, J.A. Three-dimensional extrusion bioprinting of single-and double-network hydrogels containing dynamic covalent crosslinks. J. Biomed. Mater. Res. Part A 2018, 106, 865-875. [CrossRef]

36. Gevorkian, A.; Morozova, S.M.; Kheiri, S.; Khuu, N.; Chen, H.; Young, E.; Yan, N.; Kumacheva, E. Actuation of Three-DimensionalPrinted Nanocolloidal Hydrogel with Structural Anisotropy. Adv. Funct. Mater. 2021, 31, 2010743. [CrossRef]

37. Discher, D.E.; Janmey, P.; Wang, Y.-1. Tissue cells feel and respond to the stiffness of their substrate. Science 2005, 310, 1139-1143. [CrossRef]

38. Arora, A.; Kothari, A.; Katti, D.S. Pericellular plasma clot negates the influence of scaffold stiffness on chondrogenic differentiation. Acta Biomater. 2016, 46, 68-78. [CrossRef] [PubMed]

39. Lee, H.J.; Seo, Y.; Kim, H.S.; Lee, J.W.; Lee, K.Y. Regulation of the viscoelastic properties of hyaluronate-alginate hybrid hydrogel as an injectable for chondrocyte delivery. ACS Omega 2020, 5, 15567-15575. [CrossRef] 